\title{
The molecular phylogeny and taxonomy of endophytic fungal species from the leaves of Vitex negundo $\mathrm{L}$.
}

\author{
Ramesh $\mathrm{V}^{1}$, Arivudainambi $\mathrm{USE}^{2}$ and Rajendran $\mathrm{A}^{3}$ \\ ${ }^{1}$ Department of Botany, Vivekananda College, Tiruvedakam West - 625 234, Madurai, Tamilnadu, India \\ ${ }^{2}$ Department of Chemistry, VHNSN College, Virudhunagar - 626 00, Tamilnadu, India \\ ${ }^{3}$ Department of Botany, VHNSN College, Virudhunagar - 626 00, Tamilnadu, India
}

Ramesh V, Arivudainambi USE, Rajendran A 2017 - The molecular phylogeny and taxonomy of endophytic fungal species from the leaves of Vitex negundo L. Studies in Fungi 2(1), 26-38, Doi 10.5943/sif/2/1/4

\begin{abstract}
Enormous fungal species live within the healthy plant tissues, some of which presumably occur in a symbiotic association with host. Some fungal endophytes are widespread and can be found in many different plant species, whereas others are highly specific to single hosts. In this study, we isolated three endophytic fungi from the medicinal plant Vitex negundo. They were identified based on morphological characteristics such as size, shape, and colour of the spore and it was reinforced by $18 \mathrm{~s}$ rRNA gene sequence analysis. The phylogenetic tree showed that C. gloeosporioides VN1 and Pestalotiopsis virgatula VN2 were closely relationship between. But they were not closely relationship between the other endophytic fungal species that were obtained from geographically different part of the world. This aspect can be further explored to understand the relationships between plant hosts and their fungal endophyte.
\end{abstract}

Key words - Endophytic fungi - MEGA 6.0 - phylogenetic relationship - rRNA

\section{Introduction}

Endophytes are to be found in virtually every plant on earth. They reside in the living tissues of the host plant and do so in a variety of relationships ranging from symbiotic to pathogenic (Strobel et al. 2004). Endophytes receive nutrition and protection from the host plant, while the host plant may benefit from enhanced competitive abilities and increased resistance to herbivores, pathogens, and various abiotic stresses by attaining the metabolic substances of endophytes (Saikkonen et al. 1998, Tan \& Zou 2001, Zhang et al. 2006). Endophytic fungi have been found in all plant families so far investigated, which represent many species in different climatic regions of the world (Spurr \& Welty 1975, Petrini \& carroll 1981, Petrini et al. 1992). Endophytes have been reported from all major groups of plants including algae (Zuccaro et al. 2008, Suryanarayanan et al. 2010), lichens (Suryanarayanan et al. 2005), mosses (Schulz et al. 1993), ferns (Petrini et al. 1992), conifers (Giordano et al. 2009) and angiosperms (Saikkonen 2007), and may persist even in aseptically cultured plants (Lucero et al. 2008). Endophytic fungi are reported from plants that grow in various environments including tropic (Mohali et al. 2005), temperate (Ganley et 
al. 2004), xerophytic (Suryanarayanan et al. 2005) coastal mangroves (Kumaresan \& Suryanarayanan 2001, Okane et al. 1998) and aquatic environment (Sati \& Belwal 2005). Environment plays an important role on endophyte biodiversity, while the species diversity is dependent upon the nature of the host plant and their ecological location.

Medicinal plants have been recognized as a repository of fungal endophytes with novel metabolites of pharmaceutical importance (Strobel et al. 2004, Wiyakrutta et al. 2004, Kumar et al. 2005, Tejesvi et al. 2007). Plant with pharmaceutical importance is being exploited because of their healing properties. However, large scale harvesting of medicinal plants has already become a major threat to biodiversity. As an alternative, microbe which lives inside the plants (endophytes) may often become a tremendous potential source of therapeutic compounds.

Traditional classification and identification of endophytic fungi depends upon microscopic features, colony characteristics on artificial media and biochemical reactions (Sutton \& Cundell 2004). This kind of methods have served in the past but they have major drawbacks as they cannot be applied to non cultivatable organisms and occasionally biochemical characteristic of some organisms do not fit into the patterns of any known genus and species. Amplification and sequencing of target regions within the ribosomal DNA gene complex has emerged as a useful adjunctive tool for the identification of endophytic fungi and does not depend on fungus sporulation for identification (Buzina et al. 2001, Iwen et al. 2002, Rakeman et al. 2005, Schwarz et al. 2006).

The key elements for the evolution of the endophytes are quite complex, involving various types of interactions between the host plant, numerous levels of happenstance, and multidirectional flows, they are also influenced by random events, such as living and non living factors, which guide the process of co-evolution between endophytic fungi and their hosts (Saikkonen et al. 2004).

Eventhough knowledge regarding the ecology, life cycle and phylogeny of endophytic fungi has quickly increased and accumulated over the last three decades, questions concerning their evolutionary origin, species and ecological role are not yet completely understood (Saikkonen et al. 2004). There is good reason to believe that partnership coevolution was essential for the survival of both, and in this case, the symbiosis was mutualistic (Read et al. 2000).

The ribosomal DNA (rDNA) is present in all organisms and its evolution is rapid, so it is used to discriminate related species or even varieties of the same species. The ITS regions are flanked by preserved segments (18S, 5.8S and $28 \mathrm{~S}$ genes). These preserved regions provide the information about the phylogeny and the taxonomic level, since their evolution is slow and they are highly similar within different taxa

Considering the importance of the Vitex negundo L. as a medicinal plant, the aim of the present work was to determine the phylogenetic relationship of three endophytic fungi comparison with other endophytes from different geographic region that were deposited in NCBI database.

\section{Materials \& Methods}

\section{Plant material and study area}

Healthy leaves of medicinal plant Vitex negundo L. were collected from various seasons in Botanical garden, Department of Botany, VHNSN College, Virudhunagar, Tamil Nadu, India (Fig.1) Leaves were cut from the plants and placed in plastic bags after removal of excess moisture. The leaf samples were stored at $4^{\circ} \mathrm{C}$. 


\section{Isolation of endophytic fungi}

The leaf samples were washed thoroughly under running tap water and air dried before they were processed. An endophytic fungus was isolated according to the reported protocol (Petrini 1986), which was modified slightly based on preliminary testing. All the leaf samples were washed twice in distilled water and then surface sterilized by immersion for $1 \mathrm{~min}$ in $70 \% \mathrm{v} / \mathrm{v}$ ethanol, $4 \mathrm{~min}$ in sodium hypochlorite (3\% v/v available chlorine) and $30 \mathrm{~s}$ in $70 \% \mathrm{v} / \mathrm{v}$ ethanol, and further washed three times in sterilized distilled water for $1 \mathrm{~min}$ each time. After surface sterilization, the samples were cut into 5-7 $\mathrm{mm}$ pieces and aseptically transferred to Petri plates containing potato dextrose agar (PDA) with $50 \mu \mathrm{g} / \mathrm{mL}$ of streptomycin to suppress bacterial growth. The Petri plates were incubated at $30^{\circ} \mathrm{C}$ with normal daily light and dark periods. The plates were examined daily for up to 1 month for the development of fungal colonies growing on the leaf segments. The fungi growing on the leaf tissue were subsequently transferred onto fresh PDA plates without antibiotics.

\section{Microscopic analysis}

The endophytic fungi were grown on PDA at $30{ }^{\circ} \mathrm{C}$ for $7-9 \mathrm{~d}$, and the formation of conidia was examined under a microscope. Moreover, slide culture technique was also used to observe the morphology of the fungi. For spore dimensions determinations we were used 50 spores. Lacto phenol cotton blue and distilled water were used as mounting media for microscopic analysis. Photography was carried out with the assistance of light microscope and binocular microscope (COSLAP) with computer attached. The isolated endophytic fungi were identified at Centre for Advanced Studies in Botany, University of Madras, Tamil Nadu, India.

\section{DNA extraction, amplification and sequencing}

Fungal isolates were incubated a week at $30{ }^{\circ} \mathrm{C}$ on PDA. The mycelia were harvested and transferred into $2 \mathrm{ml}$ plastic tubes using a sterile spatula and lyophilized for DNA isolation. Genomic DNA was isolated by using the method of Doyle \& Doyle (1987). Further, the ribosomal DNA amplification, ITS1-5.8S-ITS2 region, was carried out and primers ITS1 and ITS4 were used as described by White et al. (1990). Isolates of 18s rRNA fungal sequences obtained were submitted to GenBank (NCBI, USA) (accession numbers: HQ191217, JF795287 and JF795288). All the studies of DNA isolation and sequencing were done by Synergy Scientific Services, Chennai.

\section{Phylogenetic analysis}

Phylogenetic analysis was conducted in MEGA 6 software (Tamura et al. 2007). Sequenced ITS1-5.8S-ITS2 regions were aligned initially using the alignment algorithm Clustal W (Thompson et al. 1997) with the gap open penalty 7.0 and gap extension penalty 4.0. Due to some variation in areas of ITS1 and ITS2 regions, an alignment was then improved manually. The evolutionary history was inferred using the neighbor joining method (Saitou \& Nei 1987). All positions containing gaps with missing data were eliminated from the dataset. Strengths of internal branches of resulting trees were statistically tested by the bootstrap analysis of 1000 replications (Felsenstein 1985). Additional sequences were retrieved from GenBank (Table 1).

\section{Results}

\section{Taxonomy}

\section{Fungal isolate VN1}

The morphological characteristics of the endophytic fungal isolate VN1 was observed 
on PDA after 7 days of growth at $30{ }^{\circ} \mathrm{C}$. Colonies on PDA was circular, raised, at first orange-white, sometimes grey and becoming pale orange with age, aerial mycelia white dense, cottony without visible conidial masses, reverse bright orange but sometimes yellowish-brown to olive-brown and very slow-growing. Acervuli and Setae were absent in culture. Conidia were hyaline, unicellular and cylindrical with obtuse apices and tapering bases. Average conidial size was $14.7 \times 3.8 \mu \mathrm{m}$. (Fig. 2).

Traditionally, identification of Colletotrichum sp. have been based on size and shape of conidia and culture characteristics such as colony colour, growth rate and texture (Smith et al. 1990). Morphological characteristics allowed the identification of the endophytic fungal isolate VN1 as Colletotrichum gloeosporioides, which was reinforced by the sequence of its $18 \mathrm{~S}$ rRNA that gave a $91 \%$ sequence similarity to those accessible at the BLAST of Colletotrichum gloeosporioides (Fig. 3). The endophytic fungal sequence was deposited at GenBank with Accession No. HQ191217.

\section{Fungal isolate VN2}

The fungus growing on PCA was pale buff with sparse aerial mycelium and acervuli containing black, slimy spore masses (Fig.4). All isolates had 5-celled conidia, apical and basal cells were hyaline, while the three median cells were olivaceous; the upper two were slightly darker than the lower one. Conidia were $20.3 \times 6.8 \mu \mathrm{m}$. They were typically three apical appendages averaging $16.8 \mu \mathrm{m}$ long. The average basal appendage was $3.8 \mu \mathrm{m}$ long (Fig. 4). The fungal isolate was initially identified by comparing morphological and cultural characteristics (Size of the conidia, color and length of median cells, length and number of apical appendages and length of basal appendage) to those described in Guba's monograph of Monochaetia and Pestalotia (Guba 1961).

Morphological characteristics allowed the identification of the endophytic fungal isolate VN2 as Pestalotiopsis virgatula which was reinforced by the sequence of its $18 \mathrm{~S}$ rRNA gene that gave a $98 \%$ sequence similarity to those accessible at the BLAST of Pestalotiopsis virgatula (Fig. 5). The endophytic fungal sequence was deposited at GenBank Accession No. JF795287.

Based on the above morphological and molecular characteristics the endophytic fungus was identified and designated as Pestalotiopsis virgatula VN2. The endophytic fungus $P$. virgatula $\mathrm{VN} 2$ belongs to the class Ascomycota.

\section{Fungal Isolate VN3}

The fungal isolate VN3 grows rapidly on PDA medium and matures within $5 \mathrm{~d}$. The colony is flat, downy to cottony and may eventually be covered by greyish, short, aerial hyphae. The reverse side is typically brown to black due to pigment production (Fig. 6). They have septate, dark hyphae. They bear simple or branched large conidia $(8-16 \times 23-50 \mu \mathrm{m})$ which have both transverse and longitudinal septations. These conidia may be observed singly or in acropetal chains and may produce germ tube. They are ovoid to obclavate, darkly pigmented muriform, smooth or roughened. The end of the conidium nearest the conidiophere is round while it tapers towards the apex (Fig. 6).

Morphological characteristics of fungus allowed the identification of the endophytic fungal isolate VN3 as Alternaria alternata which was reinforced by the sequence of its $18 \mathrm{~S}$ rRNA gene that gave a 95\% sequence similarity to those accessible at the BLAST of Alternaria alternata. The endophytic fungal sequence was deposited at GenBank with Accession No. JF795288 (Fig. 7). This endophytic fungus A. alternaria VN3 belongs to the class Ascomycota. 


\section{Phylogenetic analysis}

Phylogenetic relationships inferred from ITS1-5.8S-ITS2 region sequences of three species are shown in Figure 8. The tree is divided into three main clusters (A, B and C) and further each one divided into two sub-clusters like A1, A2, B1, B2, C1 \& C2. Based on the evolution, among the present three fungal endophytes Colletotrichum gloesporoides VN1 and Pestalotiopsis virgatula VN2 were grouped into the single sub cluster B2. Another present endophytic fungal species of Alternaria alternata VN3 was located in the subclaade A1. In sub-cluster A1 Colletotrichum gloeosporoides, Pestalotiopsis funerea strain SYJM13, Pestalotiopsis sp. Strain F4875 and Alternaria alterna VN3 were grouped together. Pestalotiopsis sp. MA165, Pestalotiopsis sp. MA129 and A. compacta strain IR13 were grouped together in sub-cluster A2. In sub-cluster B1 C. gloeosporiodes strain FL1-ML2, Alternaria sp. Abs and Pestalotiopsis sp. Z4-08 were grouped together. The phylogenetic tree results showed $C$. gloeosporioides $\mathrm{VN} 1$ and Pestalotiopsis virgatula VN2 were closely relationship between. But they were not closely relationship between the other endophytic fungal species that were obtained from geographically different parts of the world.

\section{Discussion}

Vitex negundo L. (Verbenaceae) is a woody, aromatic shrub growing to a small tree. It commonly bears tri or penta foliate leaves on quadrangular branches, which give rise to bluish purple colored flowers in branched tomentose cymes. It thrives in humid places or along water courses in wastelands and mixed open forests and has been reported in many countries. It is grown commercially as a crop in parts of Asia, Europe, North America and the West Indies (de Padua et al. 1999). It is an important medicinal plant used in the traditional medicine and has a variety of pharmacological activities. Hence, in the present study we were used this plant as a host for endophytic fungal isolation. Three endophytic fungal species were isolated from leaves of $V$. negundo.

Table 1 Species and GenBank accession number used in the study

\begin{tabular}{lll} 
Name of the Species & Geographic origin & GenBank No \\
& & \\
\hline Colletotrichum gloeosporioides VN1 & & HQ191217 \\
Colletotrichum gloeosporioides Strain JS1-SAS12 & India & KP900300 \\
Colletotrichum gloeosporioides Strain FL1-ML2 & China & KP900236 \\
Colletotrichum gloeosporioides Strain W-2 & China & HQ845101 \\
Colletotrichum gloeosporioides Strain JL5 & China & KM513573 \\
Colletotrichum gloeosporioides Strain FL1-CJL1 & China & KP900235 \\
Pestalotiopsis virgatula VN2 & India & JF795287 \\
Pestalotiopsis funerea strain SYJM13 & India & JF923833 \\
Pestalotiopsis sp. Z4-08 & China & HQ262524 \\
Pestalotiopsis sp. AE-2013 Strain F4875 & Panama & KF746126 \\
Pestalotiopsis sp. MA129 & Thailand & GQ254681 \\
Pestalotiopsis sp. MA165 & Thailand & GU592005 \\
Alternaria alternata VN3 & India & JF795288 \\
Alternaria compacta Strain IR13 & Iran & KU323573 \\
Alternaria sp. HT-M18-LS & China & KJ527010 \\
Alternaria sp. HT-M18-L & China & KJ527009 \\
Alternaria sp. Abs & Serbia & JF742668 \\
Alternaria sp. B5A & USA & EF432299 \\
\hline
\end{tabular}

Asterisks indicate the sequences obtained from the present study 
Endophytic fungal species are complex anamorphic genus. For example Pestalotiopsis was established by Steyaert (1949). It can be lived as saprobes, plant pathogens or endophytes (Suto \& Kobayashi 1993, Rivera \& Wright 2000, Karakaya 2001, Gonthier et al. 2006, Sousa et al. 2004). The identification of endophytic fungal species based on morphology is however, complicated because there are few morphological characters available to distinguish taxa at the species level. Hence, nuclear small subunit ribosomal RNA gene regions are usually used as a molecular tool to analyze fungal taxa at a family or order level and ITS regions are commonly used to examine phylogenetic positions or relationship at a species or intra species level. Morphological characters are important in identifying Pestalotiopsis species (Steyaert 1949, Guba 1961, Sutton 1980, Nag Raj 1993). Characters used however are few and often overlap. This results in identification problems and difficulties in differentiating species. In the case of Colletotrichum sp. molecular phylogeny has been helpful in establishing species concepts (Photita et al. 2005).

Our fungal strains formed a segregated claade with A. alternata, C. gloeosporioides and $P$. virgatula supported by low bootstrap values of 38,18 and $46 \%$, respectively. Similar results were obtained in the phylogenetic analysis of Xylaria species from Western Gahts of Curtallum Hills (Ramesh et al. 2012). Phylogenetic analysis, based on rDNA sequencing, enabled us to show that there is genetic variability among the isolates of the three endophytic fungi. Moreover, they were not closely related between the other endophytic fungal species that were obtained from geographically different parts of the world.

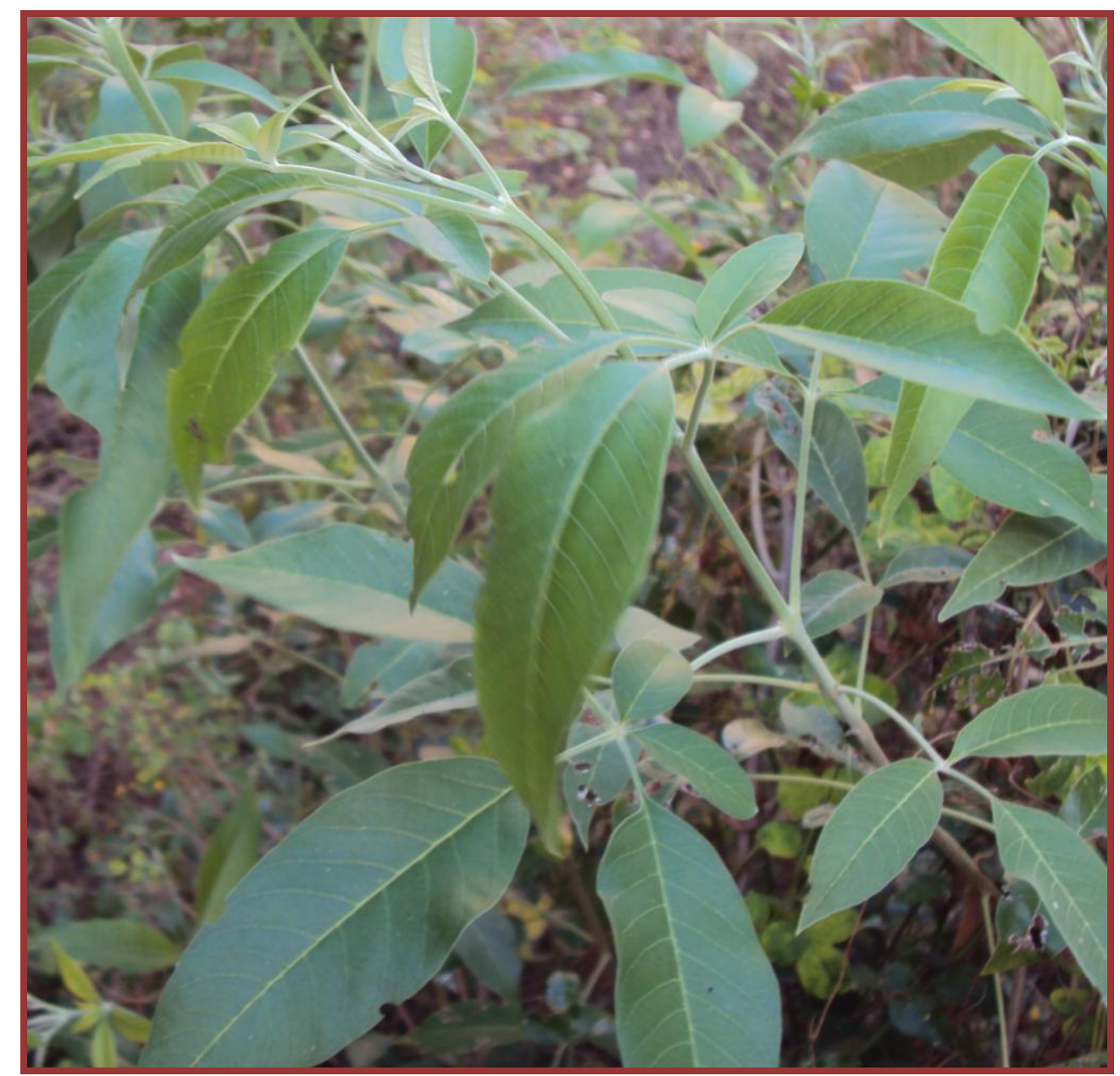

Fig. 1 - Medicinal plant Vitex negundo L. 

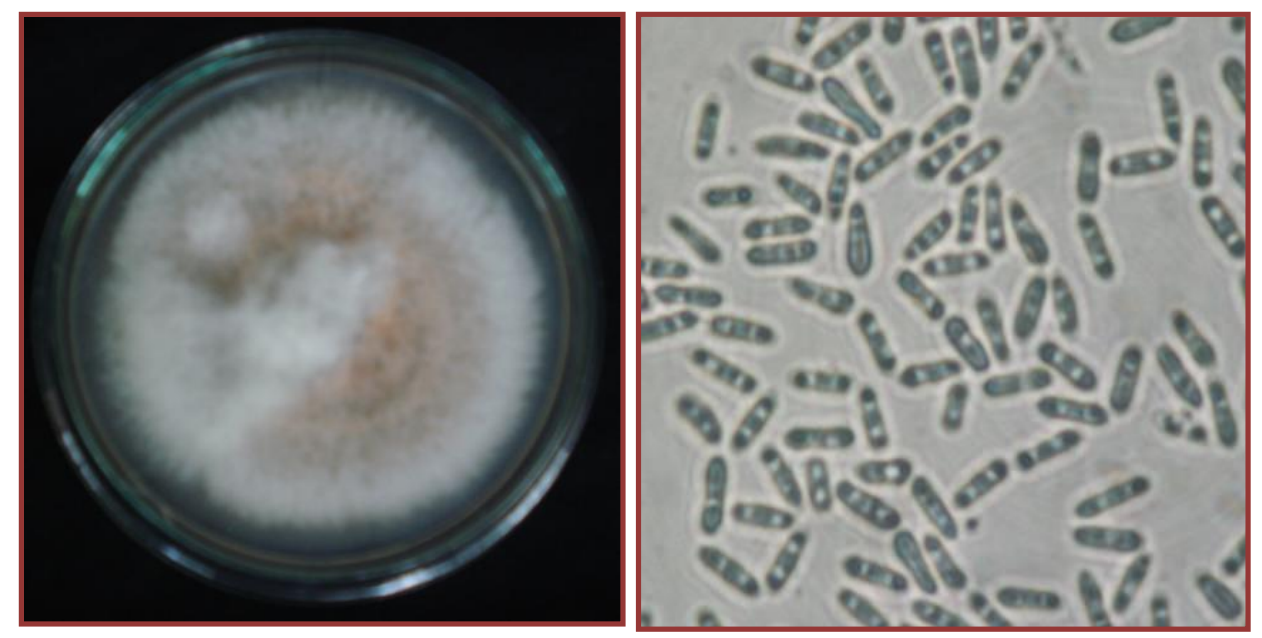

Fig. 2 - Morphology characteristics of Colletotrichum gloeosporioides

TCTACACCCTTTGTGACATACCTATAACTGTTGCTTCCGCGGGTAAGGTCCCCGT GACCCTCCCGGGCTCCCGCCCCCCGGGCGGGTCGGCGCCCGCCCGAAGAAAACC CAACTCTGATTTAACGACCTTTCTTCTGAATGGTACAAGCAAATAATCCAAACTT TTAACAACGGATCTCTTGGTTCTGGCATCCATGAAAAACGCAGCGAAATGCGAT AAGTAATGTGAATTGCAGAATTCAGTGAATCATCGAATCTTTGAACGCACATTGC GCCCGCCCACATTCTGGCGGGCATGGCTGTTCCAACGTCCTTTTCAACCCTCAAG CTCTGCTTGGTGGTGGGGGCCCTACACTGATGTTAGGCCCTCAAGGTAATGGCGG AACCCTCCCCGAACCCCCTTTGCGTTATAACTTTTACGTCTCGCACTGGGGATCC GGAAGGGACTCCTTGCCCGAAAACCCCCAATTTTTCCAAAGGTTGACCTCGGATC AGGTAAGAAATACCCCGCTGAACTTTAACATATCAATAACCGGAAGA

Fig. 3 - 18S rRNA sequence of Colletotrichum gloeosporioides

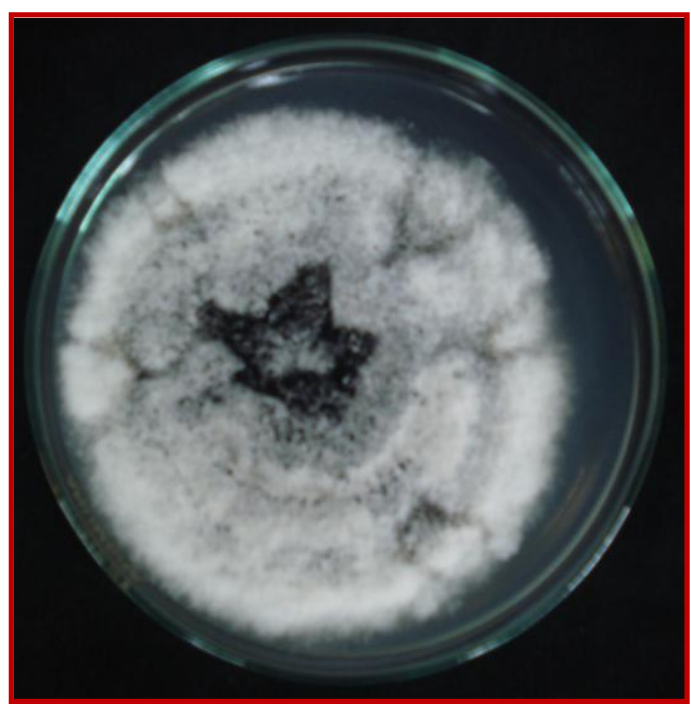

Colony morphology

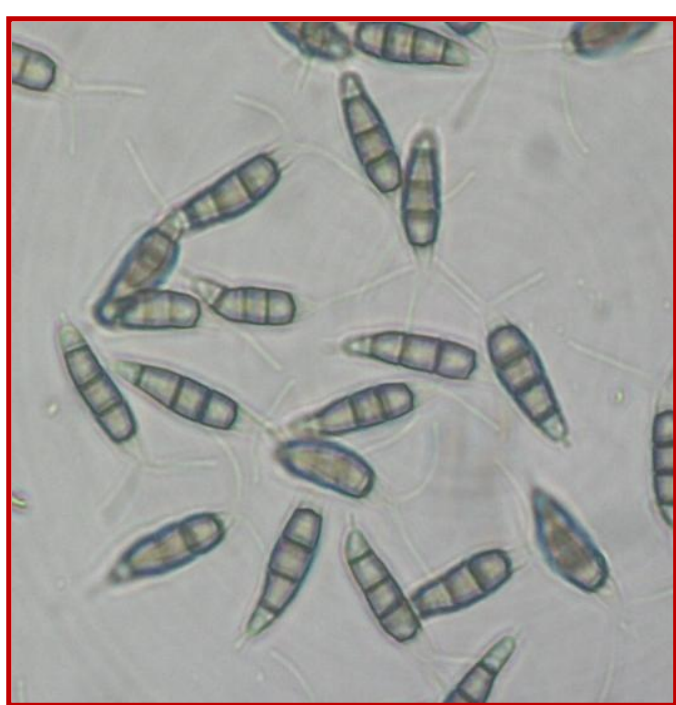

Conidial spore $(200 \mathrm{X})$

Fig. 4 - Morphology characteristics of Pestalotiopsis virgatula 
TGTGAACTTACCTTTTGTTGCCTCGGCAGAAGTTATAGGTCTTCTTATAACTGCTG CCGGTGGACCATTAAACTCTTGTTATTTTATGTAATCTGAACGTCTTATTTTAATA AGTCAAAACTTTCAACAACGGATCTCTTGGTTCTGGCATCGATGAAGAACGCAGC GAAATGCGATAAGTAATGTGAATTGCAGAATTCAGTGAATCATCGAATCTTTGAA CGCACATTGCGCCCATTAATATTCTAGTGGGCATGCCTGTTCGAGCGTCATTTCA ACCCTTAAGCCTAACTTAGTGTTGGGGAATCTACTTCTTTATAGTTGTAGTTCCTG AAATACAACGGCGGATTTGTAGTATCCTCTGAGCGTAGTAATTTTTTTCTCGCTTT TGTTAAGTGCTATAACTCCCAGCCGCTAAACCCCCAATTTTTTGTGGTTGACCTCG GATCACGTAGGAATACCCGCTGAACTTAAGCATATCAATAAGCGGAGGAAATAA CCTTTTTTAGTTTTCTAATCTCCATCCATGTGACTTACCTTTAGTTGACTCGCAAA GTTATATGTCTTCTT

Fig. 5 - 18S rRNA sequence of Pestalotiopsis virgatula
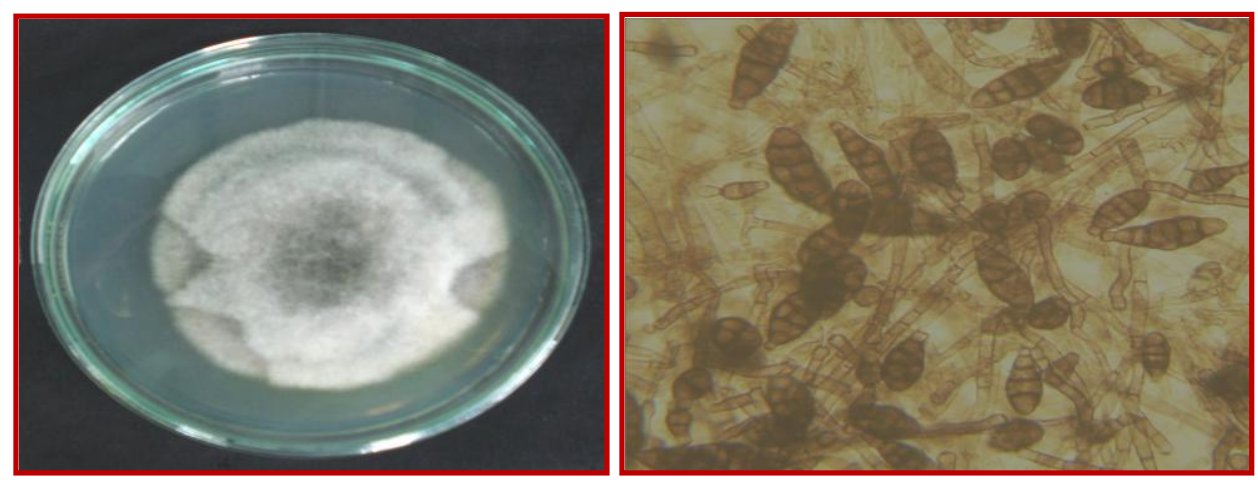

Fig. 6 - Morphology characteristics Alternaria alternata

TCTCGGGGTTACAGCCTTGCTGAATTATTCACCCTTGTCTTTTGCGTACTTCTTGTT TCCTTGGTGGGTTCCCCCCCCACTAAGACAAACATAAACCTTTTGTAATTGCAAT CCGCGTCAGTAACAAATTAATAATTACAACTTTCAACAACGGATCTCTTGGTTCT GGCATCGATGAAGAACGCAGCGAAATGCGATAAGTAGTGTGAATTGCAGAATTC AGTGAATCATCGAATCTTTGAACGCACATTGCGCCCTTTGGTATTCCAAAGGGCA TGCCTGTTCGAGCGTCATTTGTACCCTCAAGCTTTGCTTGGTGTTGGGCGTCTTGT CTCTAGCTTTGCTGGAGACTCCCTTAAAGTAATTGGGCAGCCGGCCTACTGGTTT TCGGAGCGCAGCACAAGTCCCCACTCTCTATCAGCAAAGGTCTAACCATCCCATT AAGCCTTTTTTTTTCAACTTTTTGACCCTCGGGATCCAGGTAGGGAATACCCCGCT GAAACTTAAACCATAATCAATAAGCGGAAGAAAAAAATCATTACACAAATAATG AAAGGGCGGGCTGGAATC

Fig. 7 - 18S rRNA sequence of Alternaria alternata

Endophytic fungi are everywhere and occur within all plant parts in various ecosystems, but the geographic differences in endophyte diversity, community composition and host preference have not been well documented. To understand the ecology of fungal endophytes, data regarding fundamental parameters of endophyte symbiosis are require from regional to continental scales and encompassing entire ecosystems (Peay et al. 2010). It is hoped that powerful, high throughput molecular techniques like sequencing technology will make the global assessment of endophyte diversity a reality and open up the 'black box' of fungal ecology. 


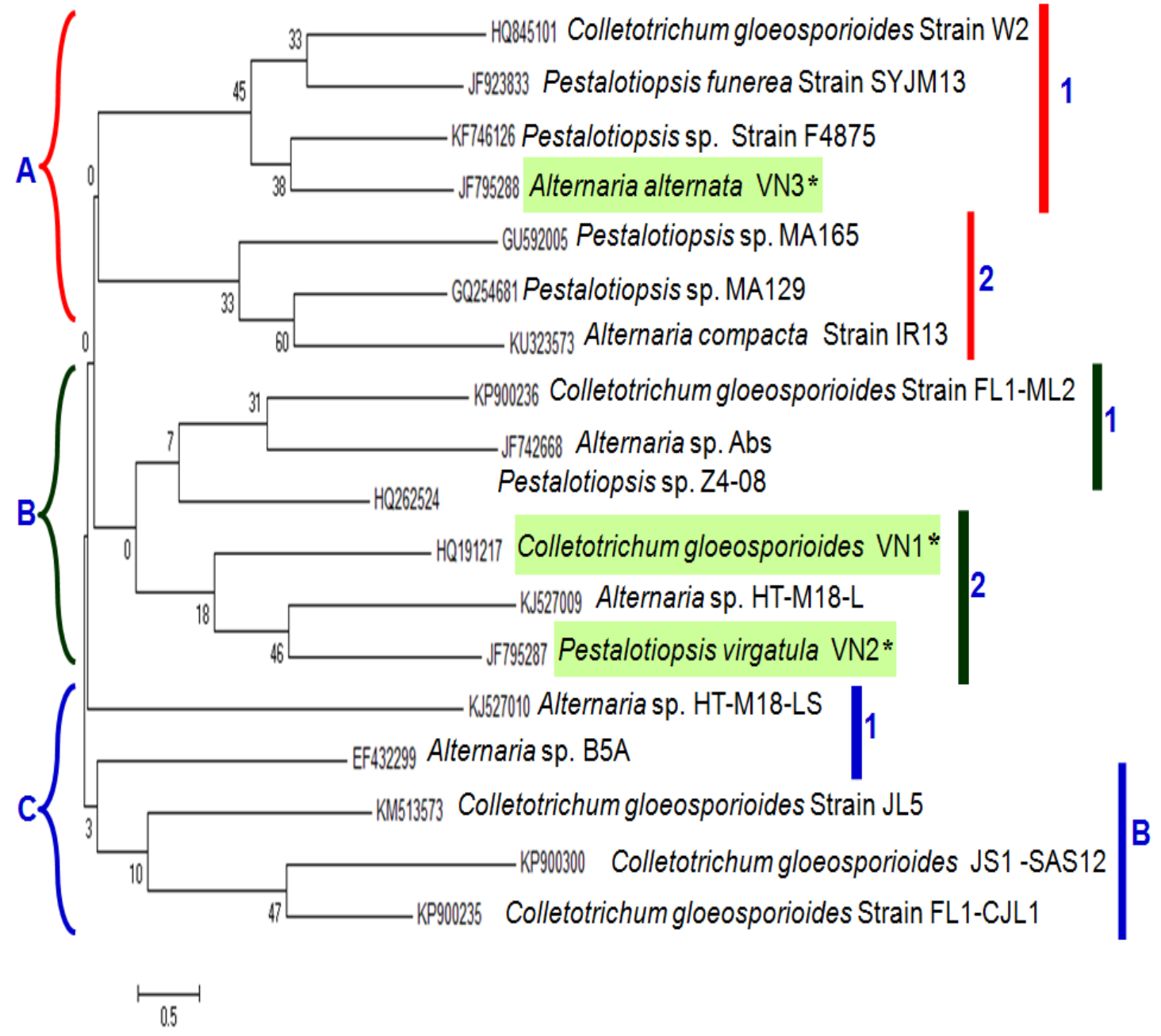

Fig. 8 - Phylogenetic relationship between three endophytic fungal species, inferred from ITS nucleotide sequence data. Bootstrap values are shown for those branches that had $>10 \%$ support in a bootstrap analysis of 1000 replicates. The numbers of nucleotide changes among taxa are represented by branch length and scale bar equals the number of nucleotide substitutions per site. Asterisks indicate the sequence obtained from the present study. A, B \& $\mathrm{C}$ indicates major clusters and $1 \& 2$ indicates sub-clusters referred to in the text.

\section{Acknowledgments}

Author thanks the Managing Board of Virudhunagar Hindu Nadar's Senthikumara Nadar College, Virudhunagar-626 001, Tamil Nadu, India for providing research facilities.

\section{References}

Buzina W, Lang-Loidolt D, Braun H, Freudenschuss K, Stammberger H. 2001 Development of molecular methods for identification of Schizophyllum commune from clinical samples. Journal of Clinical Microbiology 39, 2391-2396.

de Padua LS, Bunyapraphatsara N, Lemmens RHMJ. 1999 - Medicinal and Poisonous Plants, Plant Resources of South East Asia, Backhuys Publishers, Leiden, 1999.

Felsenstein J. 1985 - Confidence limits on phylogenies: an approach using the bootstrap. Evolution 39, 783-791. 
Ganley RJ, Brunsfeld SJ, Newcombe G. 2004 - A community of unknown, endophytic fungi in western white pine. Proceedings of the National Academy of Sciences USA 101, 10107-10112.

Giordano L, Gonthier P, Varese GC, Miserere L, Nicolotti G. 2009 - Mycobiota inhabiting sapwood of healthy and declining Scots pine (Pinus sylvestris L.) trees in the Alps. Fungal Diversity 38, 69-83.

Gonthier P, Massimo G Nicolotti G. 2006 - Effects of water stress on the endophytic mycota of Quercus robur. Fungal Diversity 21, 69-80.

Guba EF. 1961 - Monograph of Pestalotioa and Monochaetia. Harvard University Press, Cambridge, MA.

Iwen PC, Hinrichs SH, Rupp ME. 2002 - Utilization of the internal transcribed spacer regions as molecular targets to detect and identify human fungal pathogens. Medical Mycology 40, 87-109.

Karakaya A. 2001 - First report of infection of kiwifruit by Pestalotiopsis sp. in Turkey. Plant Disease 85, 1028.

Kumar DSS, Lau CS, Wan JMF, Yang D, Hyde KD. 2005 - Immunomodulatory compounds from Pestalotiopsis leucothës (HKUCC 10197), an endophytic fungus of Tripterygium wilfordii. Life Sciences 78, 147-156

Kumaresan V, Suryanarayanan TS. 2001 - Occurrence and distribution of endophytic fungi in a mangrove community. Mycological Research 105, 1388-1391.

Lucero ME, Barrow JR, Osuna P, Reyes I, Duke SE. 2008 - Enhancing native grass productivity by co-cultivating with endophyte Laden calli. Rangeland Ecology Management 61, 124-130.

Mohali SR, Burgess TI, Wingfield MJ. 2005 - Diversity and host association of the tropical tree endophyte Lasiodiplodia theobromae revealed using simple sequence repeat markers. Forest Pathology 35, 385-396.

Nag Raj TR. 1993 - Coelomycetous anamorphs with appendage bearing conidia. Mycologue Publications, Waterloo, Ontario, Canada.

Okane I, Nagagiri A, Ito T. 1998 - Endophytic fungi in leaves of ericaceous plants. Canadian Journal of Botany 76, 657-663

Petrini O. 1986 - Taxonomy of endophytic fungi of aerial plant tissues. Microbiology of the Phyllosphere (Fokkema NJ \& van den Heuvel J, eds), pp. 175-187. Cambridge University Press, Cambridge.

Petrini O, Carroll GC. 1981 - Endophytic fungi in foliage of some Cupressaceae in Oregon. Canadian Journal of Botany 59, 629-636.

Petrini O, Fisher PJ, Petrini LE. 1992 - Fungal endophytes of bracken (Pteridium aquilinum) with some reflections on their use in biological control. Sydowia 44, 282-293.

Photita W, Taylor PWJ, Ford R, Hyde KD, Lumyong S. 2005 - Morphological and molecular characterization of Colletotrichum species from herbaceous plants in Thailand. Fungal Diversity 18, 117-133.

Rakeman JL, Bui U, La Fe K, Chen YC, Honeycutt RJ, Cookson BT. 2005 - Multilocus DNA sequence comparisons rapidly identify pathogenic molds. Journal of Clinical Microbiology 43, 3324-3333.

Ramesh V, Thalavaipandian A, Karunakaran C, Rajendran A 2012 - Identification and Comparison of Xylaria curta and Xylaria sp. from Western Ghats-Courtallum Hills, India. Mycosphere 3, 607-615.

Read DJ, Duckett JG, Francis R, Ligrone ARU. 2000 - Symbiotic fungal associations in 'lower' land plants. Philosophical Transactions of the royal society B 355, 815-831

Rivera MC, Wright ER. 2000 - First report of azalea petal blight caused by Pestalotiopsis guepinii in Argentina. Plant Disease 84, 100. 
Saikkonen K. 2007 - Forest structure and fungal endophytes. Fungal Biology Reviews 21, 67-74.

Saikkonen K, Faeth SH, Helander M, Sullivan TJ. 1998 - Fungal endophytes: a continuum of interaction with host plants. Annual Review of Ecology, Evolution and Systematics 29, 319-343.

Saikkonen K, Wali P, Helander M, Faeth SH. 2004 - Evolution of endophyte-plant symbioses. Trends Plant Science 9, 275-280.

Saitou N, Nei M. 1987 - The neighbor-joining method: a new method for reconstructing phylogenetic trees. Molecular Biology and Evolution 4, 406-425.

Sati SG, Belwal M. 2005 - Aquatic hyphomycetes as endophytes of riparian plant roots. Mycologia 97, 45-49

Schulz U, Wanke S, Draeger HJ. 1993 - Endophytes from herbaceous plants and shrubs: effectiveness of surface sterilization methods. Mycological Research 97, 1447-1450.

Schwarz P, Bretagne S, Gantier JC, Garcia-Hermoso D, Lortholary O, Dromer F, Dannaoui E. 2006 - Molecular identification of Zygomycetes from culture and experimentally infected tissues. Journal of Clinical Microbiology 44, 340-349.

Simth BJ, Black LL. 1990 - Morphological, cultural and pathogenic variation among Colletotrichum species isolated from strawberry. Plant Diseases 74, 69-67.

Sousa MF, Tavares RM, Geros H, Lino-Neto T. 2004 - First report of Hakea sericea leaf infection caused by Pestalotiopsis funerea in Portugal. Plant Pathology 53, 535.

Spurr HW, Welty RE. 1975 - Characterization of endophytic fungi in healthy leaves of Nicotiana spp. Phytopathology 65, 417-422.

Steyaert RL. 1949 - Contribution a l'etude monographique de Pestalotia de NOT et Monochaetia SACC. (Truncatella gen. nov. et Pestalotiopsis gen. nov.). Bull Jard Bot EEtat Bruxelles 19, 285-354.

Strobel G, Daisy B, Castillo U, Harper J. 2004 - Natural products from endophytic microorganisms. Journal of Natural Products 67, 257-268.

Suryanarayanan TS, Thirunavukkarasu N, Hariharan GN, Balaji P. 2005 - Occurrence of non obligate microfungi inside lichen thalli. Sydowia 57, 120-130

Suryanarayanan TS, Venkatachalam A, Thirunavukkarasu N, Ravishankar JP, Doble M, Geetha V. 2010 - Internal mycobiota of marine macroalgae from the Tamilnadu coast: distribution, diversity and biotechnological potential. Botanica Marina 53, 457468.

Suto K, Kobayashi T. 1993 - Taxonomic studies on the species of Pestalotiopsis, parasitic on conifers in Japan. Transactions of the Mycological Society of Japan 34, 323-344.

Sutton. 1980 - The Coelomycetes. Commonwealth Mycological Institute, UK.

Sutton SVW, Cundell AM. 2004 - Microbial identification in the pharmaceutical industry. Pharmacopeial Forum 30, 1884-1894.

Tamura K, Dudley J, Nei M, Kumar S. 2007 - MEGA4: Molecular Evolutionary Genetics Analysis (MEGA) software version 4. Molecular Biology and Evolution 24, 15961599.

Tan RX, Zou WX. 2001 - Endophyts: A rich source of functional metabolites. Natural Product Reports 18, 448-459.

Tejesvi MV, Kini KR, Prakash HS, Ven Subbiah, Shetty HS. 2007 - Genetic diversity and antifungal activity of species of Pestalotiopsis isolated as endophytes from medicinal plants. Fungal Diversity 24, 37-54.

Thompson JD, Gibson TJ, Plewniak F, Jeanmougin F, Higgins DG. 1997 - The CLUSTAL X windows interface: flexible strategies for multiple sequence alignment aided by quality analysis tools. 
White TJ, Bruns TD, Lee S, Taylor JW. 1990 - Amplification and direct sequencing of fungal ribosomal RNA genes for phylogenetics. In: PCR Protocols: a Guide to Methods and Applications (eds Innis MA, Gelfand D, Sninsky JS, White TJ) Academic, San Diego pp, 315-322.

Wiyakrutta S, Sriubolmas N, Panphut W, Thongon N, Danwisetkanjana K, Ruangrungsi N, et al. 2004 -Endophytic fungi with anti-microbial, anti-cancer and anti-malarial activities isolated from Thai medicinal plants. World Journal of Microbiology and Biotechnology 20, 265-272.

Zhang HW, Song YC, Tan RX. 2006 - Biology and chemistry of endophytes. Natural Product Report 23, 753-771.

Zuccaro A, Schoch CL, Spatafora JW, Kohlmeyer J, Draeger S, Mitchell J. 2008 - Detection and identification of fungi associated with the brown seaweed Fucus serratus. Applied Environmental Microbiology 74, 931-941. 